\title{
Research note: an analytical perspective on market decisions and asymmetric cost behavior
}

\section{Christian Riegler $^{1} \cdot$ Katrin Weiskirchner-Merten $^{1}$ (D)}

Received: 30 August 2018 / Accepted: 20 January 2020 / Published online: 7 February 2020

(C) The Author(s) 2020

\begin{abstract}
Asymmetric cost behavior has attracted the interest of many (empirical) researchers in the last years. Prior research determines several sources of this behavior such as resource adjustment costs, uncertainties and related beliefs, agency problems, and fixed costs. Empirical studies measure firms' cost behavior using total firm costs and sales. In imperfect markets, firms react to changing market conditions by adapting output prices and quantities so that both total firm costs and sales are affected. However, changing output prices only directly affects sales and not costs. Based on an economic model, we identify market decisions (output quantity and pricing decisions) as an additional source of measured asymmetric cost behavior.
\end{abstract}

Keywords Asymmetric cost behavior $\cdot$ Market decisions $\cdot$ Pricing $\cdot$ Imperfect markets

Mathematics Subject Classification 91B99

\section{Introduction}

The empirical study by Anderson et al. (2003, in the following ABJ) documents that the cost response following a decline of the firm's activity level is smaller than the cost response to an increasing activity level (i.e., costs are sticky). The study by ABJ stimulated a large number of follow up research analyzing several cost categories (e.g. COGS or R\&D costs), several countries, or sources of cost stickiness. ${ }^{1}$ The asymmetric costs

\footnotetext{
1 See Anderson et al. (2007), Balakrishnan and Gruca (2008), Chen et al. (2012), Banker et al. (2013a), Kama and Weiss (2013), Cannon (2014), Banker and Byzalov (2014), Banker et al. (2014), Holzhacker et al. (2015), Kitching et al. (2016), Li and Zheng (2017), and Prabowo et al. (2018).
}

Katrin Weiskirchner-Merten

katrin.weiskirchner-merten@wu.ac.at

1 Department of Finance, Accounting and Statistics, Vienna University of Economics and Business, Welthandelsplatz 1, 1020 Vienna, Austria 
literature provides empirical evidence for the existence of asymmetric cost behavior around the world and identifies several determinants explaining this observation. First, firms face resource adjustment costs (Anderson et al. 2003; Banker and Byzalov 2014). In addition, prior literature determines uncertainties and related beliefs (Banker et al. 2014), agency problems related to empire building (Chen et al. 2012), and fixed costs as sources of asymmetric cost behavior (Anderson et al. 2007; Balakrishnan et al. 2014). ${ }^{2}$

It is widely accepted in the empirical literature to analyze asymmetric cost behavior using the ABJ econometric model, which uses total firm sales as output measure to examine the firms' cost behavior. ${ }^{3}$ In addition, Balakrishnan et al. (2014, in the following BLS) introduce two adaptions of the ABJ specification: a percentage specification and a scaled percentage specification. Arguments supporting the choice of total firm sales as output measure are that sales are available in standard large-scale datasets like Compustat and that it is not possible in multi-product firms using several input resources to aggregate differing physical measures of resource consumption to one single measure (Banker and Byzalov 2014, footnote 24). However, Banker and Byzalov (2014, footnote 30) point also out that changes in input prices may affect the measured asymmetric cost behavior. Relatedly, by choosing sales as output measure, output prices may also affect the measured asymmetric cost behavior. The majority of the examined firms operates on markets with imperfect competition. This provides some leeway in setting output prices. However, pricing decisions influence sales, but do not necessarily result in corresponding changes of resource consumption and costs. Thus, following the suggestion of Anderson and Lanen (2007), we study how changes on the demand side of the firm affect the cost behavior. We examine the following question: Do market decisions result in asymmetric cost behavior as measured by the (adaptions of the) ABJ specification when the firm faces imperfect competition on the final output market?

We develop a parsimonious economic model of a firm operating in differing imperfect markets (like monopoly, duopoly, and oligopoly markets). ${ }^{4}$ To single out the impact of market decisions on the measured asymmetric cost behavior, we study a setting in which none of the known sources of asymmetric cost behavior occur. Our findings show that market decisions, i.e., output quantity and pricing decisions, in imperfect markets affect the measured asymmetric cost behavior. The intuition is as follows. When the market conditions change, the firm adapts both the price and the optimal quantity under Cournot-quantity competition (and in a monopoly setting). While the price only affects sales, the quantity influences both sales and costs. Consequently, sales and costs do not change proportionally and thus, create asymmetric cost behavior. Under Bertrand-price competition with homogeneous products and costs, the firm reacts to changing market conditions by solely adapting the quantity. The price is unaffected so that sales and costs change proportionally and

\footnotetext{
${ }^{2}$ An extensive literature review is provided by Banker and Byzalov (2014) and Banker et al. (2018).

${ }^{3}$ The ABJ specification is for example used by Calleja et al. (2006), Balakrishnan and Gruca (2008), Chen et al. (2012), Banker et al. (2013a), Banker et al. (2013b), Cannon (2014), Holzhacker et al. (2015), Kitching et al. (2016), Subramaniam and Watson (2016), and Li and Zheng (2017).

${ }^{4}$ The analytical model allows us to non-ambiguously identify the effect market conditions have on a firm's cost behavior. This is an advantage over simulations and empirical analyses, where the findings are not valid in general.
} 
the firm exhibits symmetric cost behavior. In sum, the firm displays measured asymmetric cost behavior when the firm adapts both the output quantity and the price in imperfect markets.

We contribute to the existing asymmetric costs literature by analytically identifying market decisions as an additional source of measured asymmetric cost behavior. Prior literature determines resource adjustment costs, uncertainties and related beliefs, agency problems, and fixed costs as sources of the asymmetric cost behavior. When the firm's activity level changes, managers have to adjust the resources to the firm's needs. The adjustment may be costly depending on the resource's characteristics. Adjustment costs may range from almost zero (e.g. direct material for production) over an intermediate level (e.g. employee costs) to almost prohibitively costly (e.g. plant and equipment). For the adjustment decision, managers trade off adjustment costs and (future) benefits of the adjustment (Anderson et al. 2003; Banker and Byzalov 2014). Specifically, if a manager expects only a short-run decrease of the firm's activity level, the decision to keep slack resources may save on future costs of reinstalling the same resource again, offering in total a higher profit to the firm (Banker et al. 2014). Agency problems may cause asymmetric cost behavior when a self-interested manager maximizes personal utility at the cost of shareholder value. For example, a manager may refrain from downsizing a division because of loss of status or dismissing familiar employees (Anderson et al. 2003; Chen et al. 2012). Past managerial decisions determine a firm's fixed costs that cannot be controlled. Therefore, the existence of fixed costs leads to a non-proportional change of costs when sales change, thus causing asymmetric cost behavior (Anderson et al. 2007; Balakrishnan et al. 2014).

How much of the empirically documented asymmetric cost behavior is due to market decisions and how much is attributable to the established sources is an open issue. Our theoretical analysis suggests that market decisions affect the measured asymmetric cost behavior. Nevertheless, further empirical research is needed to estimate the size of the market decision effect. To do this, using output instead of sales for measuring the asymmetric cost behavior is helpful because our results depict that using output circumvents the market decision effect. Output quantities are rarely disclosed in annual reports or other public information sources. Therefore, the use of case studies or surveys seems appropriate for studying the size of the market decision effect and gaining deeper insight into the sources of the measured asymmetric cost behavior. When archival data is used for studying cost behavior, the market decisions need to be disentangled from the established sources of asymmetric cost behavior. Considering more market aspects (like development of output prices over time, changes in the product mix, or acknowledging the firm's presence in several markets) are helpful in achieving this aim. Segment reports or the MD\&A section of annual reports may provide helpful information on these aspects. Examining in empirical studies the market decision effect on the measured asymmetric cost behavior will foster our understanding of the magnitude and sources of the asymmetric cost behavior.

The paper proceeds as follows: Sect. 2 presents the ABJ econometric model specification and its adaptions used for measuring asymmetric cost behavior in empirical studies. Section 3 presents the economic model. Then, Sect. 4 illustrates a 
benchmark for measuring asymmetric cost behavior using quantity as output measure. The impact of market decisions on the measured asymmetric cost behavior using the ABJ and BLS (scaled) percentage specification in a monopolistic market or a market with Cournot-quantity competition is studied in Sect. 5. The effect of Bertrand-price competition is depicted in Sect. 6. Section 7 discusses the relevance of the findings and implications for empirical research.

\section{Measuring asymmetric cost behavior}

Most of the empirical research analyzing asymmetric cost behavior builds on the log-log-econometric model suggested by ABJ, which regresses changes in costs $C$ on changes in sales $S$ from period $t-1$ to period $t:^{5}$

$$
\ln \left(\frac{C_{t, i}}{C_{t-1, i}}\right)=\alpha+\beta_{1, A B J} \cdot \ln \left(\frac{S_{t, i}}{S_{t-1, i}}\right)+\beta_{2, A B J} \cdot \operatorname{dec} \cdot \ln \left(\frac{S_{t, i}}{S_{t-1, i}}\right)+\varepsilon,
$$

where $d e c$ is an indicator of value 1 if sales decline (and 0 otherwise). $\beta_{1, \mathrm{ABJ}}$ is the percentage change in costs when sales increase by $1 \%$. $\beta_{1, \mathrm{ABJ}}+\beta_{2, \mathrm{ABJ}}$ is the percentage change in costs when sales decrease by $1 \%$. Costs are sticky if the increase in costs following an increase in sales is higher than a corresponding decrease if sales decrease, i.e., $\beta_{2, \mathrm{ABJ}}<0$. For $\beta_{2, \mathrm{ABJ}}>0$, the effect is called anti-stickiness (Weiss 2010). Thus, $\beta_{2, \mathrm{ABJ}}$ measures asymmetric cost behavior.

The ABJ specification is adapted by BLS as percentage specification:

$$
\frac{C_{t, i}-C_{t-1, i}}{C_{t-1, i}}=\alpha+\beta_{1, B L S} \cdot \frac{S_{t, i}-S_{t-1, i}}{S_{t-1, i}}+\beta_{2, B L S} \cdot \operatorname{dec} \cdot \frac{S_{t, i}-S_{t-1, i}}{S_{t-1, i}}+\varepsilon,
$$

and as scaled percentage specification: ${ }^{6}$

$$
\frac{C_{t, i}-C_{t-1, i}}{S_{t-1, i}}=\alpha+\beta_{1, s B L S} \cdot \frac{S_{t, i}-S_{t-1, i}}{S_{t-1, i}}+\beta_{2, s B L S} \cdot \operatorname{dec} \cdot \frac{S_{t, i}-S_{t-1, i}}{S_{t-1, i}}+\varepsilon .
$$

The interpretation of $\beta_{2, \mathrm{j}}$ with $j \in\{B L S, s B L S\}$ as measured asymmetric cost behavior also applies to the BLS specifications.

In an analytical model, we study the impact of market decisions on the measured asymmetric cost behavior while concentrating on the cost behavior of a single firm. For identifying the firm's cost behavior, we use the three measurement specifications previously described. Determining the firm's cost behavior requires the consideration of at least one sales increase and one sales decrease. We examine a sales increase and decrease using two approaches. First, we consider a single market change that either results in increasing or decreasing sales to calculate the cost behavior measures (the single-market-change approach). Specifically, we introduce

\footnotetext{
5 The subscript ABJ denotes the ABJ specification of the econometric model.

6 The subscript BLS (sBLS) denotes the (scaled) percentage specification introduced by BLS.
} 
a baseline sales level followed by an increasing or decreasing sales level. Second, we consider the firm's market decisions for a sequence of two market changes (the sequence-of-two-market-changes approach). The sequence-of-two-market-changes approach uses the firm itself as a benchmark to determine the firm's cost behavior. In most empirical studies, the dataset comprises several years of the same firms so that the sequence-of-two-market-changes approach better fits previous research.

The analytical model allows us to calculate the firm's sales and cost increases (decreases) in a setting without errors and uncertainties. Then, focusing on a single firm and on one sales increase and one sales decrease implies that we can directly calculate the firm's cost response following an increasing (decreasing) activity level. That is, no regression is needed to determine the firm's cost behavior so that the error term $\varepsilon$ and the intercept $\alpha$ are 0 in either of the three measurement specifications. We use this and either the single-market-change or the sequence-of-twomarket-changes approach to determine the firm's cost behavior by calculating the measures $\beta_{1, \mathrm{k}}$ and $\beta_{2, \mathrm{k}}$ with $k \in\{A B J, B L S, s B L S\}$. Next, we introduce the economic model in detail.

\section{The model}

To analyze the impact of market decisions in imperfect markets on the measured asymmetric cost behavior, we develop a parsimonious economic model focusing solely on output and pricing decisions to avoid any overlapping effects with established sources of asymmetric cost behavior. Specifically, we consider a single product firm operating in a monopoly or Cournot-quantity competition. For a monopolistic firm, choosing price or output as decision variable yields the same result. Therefore, we present the monopoly case together with Cournot-quantity competition. For its product, the firm faces the linear inverse demand function $p_{t}\left(x_{t}\right)=a_{t}-b \cdot x_{t}$, where $p_{t}$ and $x_{t}$ denote the market price and the (total) market quantity of the final product in period $t$. Total market quantity is defined as $x_{t}=\sum_{i=1}^{n} x_{t, i}$, where $n$ indicates the number of competitors operating on the market. If $n=1$, the firm serves a monopoly market without any competition. For $n=2$, we observe a duopoly and with increasing $n$ an oligopoly market.

The inverse demand function's intercept $a_{t}$ measures the gross size of the market, $b$ the elasticity of demand. The market size may vary over time because of, for example, changing customer preferences and their willingness to pay. In each period, the firm chooses the output quantity. The costs of producing one unit of output is $c>0$ and neither resource adjustment nor fixed costs exist. To focus on the pure impact of the market decision, we assume that costs $c$ do not vary over time, all firms on the market face the same costs, ${ }^{7}$ the firm knows all subsequent market sizes before making the first market decision (no uncertainties and related beliefs), and no agency problem exists.

\footnotetext{
7 Given this assumption, all firms have the same market share. The results of the analysis do not qualitatively change if considering differing costs $c$ and consequently differing market shares.
} 
According to economic theory, firm $i$ maximizes its profit by choosing the optimal output quantity of the final product $x_{t, i}^{*}$. This results in the following decisions:

$$
\begin{gathered}
x_{t, i}^{*}=\frac{a_{t}-c}{b \cdot(n+1)}, \\
p_{t}^{*}=\frac{a_{t}+n \cdot c}{n+1}, \\
C_{t, i}^{*}=x_{t, i}^{*} \cdot c=\frac{c}{b \cdot(n+1)} \cdot\left(a_{t}-c\right), \\
S_{t, i}^{*}=x_{t, i}^{*} \cdot p_{t}^{*}=\frac{1}{b \cdot(n+1)^{2}} \cdot\left(a_{t}+n \cdot c\right) \cdot\left(a_{t}-c\right) .
\end{gathered}
$$

For the following analysis, we use two approaches to study changing activity levels:

(i) The single-market-change approach: in period $t=0$, the firm faces a baseline sales level stemming from a gross market size of $a_{0}$. In period $t=1$, the firm either faces an increase or decrease of sales because of a gross market size $a_{1}$ of $a_{1}>a_{0}$ or $a_{1}<a_{0}$, respectively. ${ }^{8}$

(ii) The sequence-of-two-market-changes approach: an increase of sales (comparing $t=0$ and $t=1$ ) is followed by a decrease of sales (comparing sales of $t=1$ and $t=2$ ). This corresponds with the following ranking of the gross market sizes: $a_{0}<a_{1}$ and $a_{2}<a_{1}$. We compare the size of the two changes. If the second sales change is larger (smaller) than the first change, we label this as large (small) market change. A large (small) market change occurs for $a_{0}>a_{2}$ $\left(a_{0}<a_{2}\right){ }^{9}$

The parsimonious economic model does not comprise intertemporal interdependencies so that multi-period considerations are superfluous. ${ }^{10}$

\section{Benchmark with quantities as output measure}

Most empirical studies use sales as output measure for studying the asymmetric cost behavior. That is, sales is the measure for the firm's activity level. Another potential measure is the production quantity. To illustrate the impact of market decisions

\footnotetext{
${ }^{8}$ To simplify the analysis, we assume throughout the paper $c<a_{t}$ and $a_{t}-c \geq 1 . c<a_{t}$ is to ensure production in each period to avoid unnecessary case distinctions for making the point. $a_{t}-c \geq 1$ is chosen, because we need to consider the natural logarithm of the difference $a_{t}-c$, which is always positive given to this assumption.

9 The results of the analysis persist if we consider the opposite sequence of gross market size changes.

10 We do not consider the time value of money. This simplification does not affect our qualitative results.
} 
on measuring asymmetric cost behavior, we consider a benchmark with production quantity as output measure in the ABJ specification of the asymmetric cost measure. Therefore, we replace sales $S_{t, i}$ by the production quantity $x_{t, i}$ in (1). In the next step, we insert the optimal output quantities and the corresponding costs according to (4) and (6) in (1) to analytically calculate $\beta_{1, A B J}$ and $\beta_{2, A B J}$. As argued before, $\varepsilon=0$ and $\alpha=0$. We do this for both the single-market-change and the sequence-of-two-market-changes approach to derive the results.

Proposition 1 With the production quantity as output measure in the ABJ specification of measuring the asymmetric cost behavior, the asymmetric cost measure $\beta_{X}^{C}$ has the following properties: ${ }^{11}$

- $\quad \beta_{1, X}^{C}=1$ and

- $\beta_{2, X}^{C}=0 .{ }^{12}$

Choosing either the single-market-change or the sequence-of-two-marketchanges approach to study changing activity levels does not affect the properties of the asymmetric cost measure.

The proof is in the "Appendix".

Costs arise because production of the firm's output requires the consumption of resources. In the setting analyzed, there is no change in the production technology. Therefore, resource consumption for producing one unit of output does not change when market conditions change. The firm faces constant costs $c$ per unit. If market conditions change, the firm adapts the production quantity to maximize profit given the new market situation. The output quantity reflects that neither the production technology nor the resource consumption per unit change. The ratio of the change in costs always equals the ratio of the change in quantity. This results in $\beta_{1, X}^{C}=1$ and $\beta_{1, X}^{C}+\beta_{2, X}^{C}=1$, i.e., $\beta_{2, X}^{C}=0$. Asymmetric cost behavior is absent. That is, with output quantity as output measure, the market decision effect is not a source of measured asymmetric cost behavior.

\section{Asymmetric cost behavior with sales as output measure}

In this section, we return to the sales-based measurement specifications of the asymmetric cost behavior presented in Sect. 2. Inserting costs (6) and sales (7) in (1) and (3) to analytically calculate the ABJ and the BLS scaled percentage measures for both the single-market-change and the sequence-of-two-market-changes approach yields the findings of Proposition 2.

\footnotetext{
11 The superscript $C$ denotes Cournot-quantity competition for $n \geq 2$ and the monopoly setting for $n=1$. The subscript $X$ indicates that the production quantity is used as output measure in the ABJ specification. 12 The same findings are obtained when the BLS (scaled) percentage specification with production quantity as output measure is used to measure the asymmetric cost behavior.
} 
Proposition 2 With the $A B J$ or the BLS scaled percentage specification, the asymmetric cost measures $\beta_{A B J}^{C}$ and $\beta_{S B L S}^{C}$ have the following properties for $k \in\{A B J, s B L S\}$ and

(i) the single-market-change approach:

- $0<\beta_{1, k}^{C}<1$ and

- $\beta_{2, k}^{C}>0$ and $0<\beta_{1, k}^{C}+\beta_{2, k}^{C}<1$,

(ii) the sequence-of-two-market-changes approach:

- $0<\beta_{1, k}^{C}<1$ and

- $\beta_{2, k}^{C}<0$ and $0<\beta_{1, k}^{C}+\beta_{2, k}^{C}<1$ if the relative size of the market changes is small,

- $\beta_{2, k}^{C}>0$ and $0<\beta_{1, k}^{C}+\beta_{2, k}^{C}<1$ if the relative size of the market changes is large.

The proof is in the "Appendix".

Proposition 2 illustrates that measured asymmetric cost behavior appears in a setting where all established sources are absent. Hence, market decisions are a source of measured asymmetric cost behavior. The intuition for this finding is as follows: The change of the gross market size captured by the demand parameter $a_{t}$ induces a change of the optimal price and the optimal output quantity to be produced. Inspection of (6) and (7) shows that sales is a quadratic function in $a_{t}$. However, costs are a linear function in $a_{t}$. Therefore, the effect of a change of $a_{t}$ is different for costs and sales. Sales and costs do not change proportionally if the firm decides to optimally adjust the output quantity according to the changes of the market size. The ratio of the change in costs is not equal to the ratio of the change in sales. This results in $0<\beta_{1, k}^{C}<1$ for $k \in\{A B J, s B L S\}$.

The effect on $\beta_{2, k}^{C}$ depends on the approach to study changing activity levels and for the sequence-of-two-market-changes approach, additionally, on the relative size of the market changes. With the single-market-change approach, the measured asymmetric cost behavior always indicates anti-stickiness.

For the sequence-of-two-market-changes approach, a small market change occurs if $a_{2}$ is larger than the initial level $a_{0}$, and $\beta_{2, k}^{C}$ is negative, indicating cost stickiness. If $a_{2}$ is even smaller than the initial level $a_{0}$ (large market change), then $\beta_{2, k}^{C}$ becomes positive, indicating anti-stickiness.

With a large market change, the sales level in $t=2$ is below the initial sales level in $t=0$. This corresponds to the single-market-change approach, where the sales level following a decrease is smaller than the baseline sales level. Therefore, the anti-stickiness result for a large market change is consistent with finding anti-stickiness with the single-market-change approach.

We repeat the analysis conducted before for the BLS percentage specification. 
Proposition 3 With the BLS percentage specification, the asymmetric cost measure $\beta_{B L S}^{C}$ has the following properties:

- $0<\beta_{1, B L S}^{C}<1$ and

- $\beta_{2, B L S}^{C}>0$ and $0<\beta_{1, B L S}^{C}+\beta_{2, B L S}^{C}<1$.

Choosing either the single-market-change or the sequence-of-two-marketchanges approach to study changing activity levels does not affect the properties of the asymmetric cost measure.

The proof is in the "Appendix".

Proposition 3 depicts that with the BLS percentage specification the asymmetric cost behavior in the form of anti-stickiness always occurs. This is true for both the single-market-change and the sequence-of-two-market-changes approach as well as for small and large market changes for the sequence-of-two-market-changes approach. Again, the form of costs and sales creates this result. While costs are linear in the gross market size, sales are quadratic. For any change in the gross market size, the cost relation is always larger than the sales relation. Consequently, the asymmetric cost measure $\beta_{2, B L S}^{C}$ exhibits anti-stickiness.

Propositions 2 and 3 illustrate that for any econometric measurement specification described in Sect. 2, market decisions are a source of measured asymmetric cost behavior.

\section{Bertrand-price competition}

Next, we consider Bertrand-price competition instead of Cournot-quantity competition for the same setting as described in Sect. 3. Each firm $(n \geq 2)$ sets the respective firm price for the firm's output simultaneously and non-cooperatively. According to the Bertrand paradox, this results in the equilibrium price equaling marginal costs (see, for example, Tirole 2001). This implies the following profit maximizing decisions of firm $i:^{13}$

$$
\begin{gathered}
p_{t}^{B^{*}}=c, \\
x_{t, i}^{B^{*}}=\frac{a_{t}-c}{n \cdot b}, \\
C_{t, i}^{B^{*}}=x_{t, i}^{B^{*}} \cdot c=\frac{c}{n \cdot b} \cdot\left(a_{t}-c\right), \\
S_{t, i}^{B^{*}}=x_{t, i}^{B^{*}} \cdot p_{t}^{B^{*}}=\frac{c}{n \cdot b} \cdot\left(a_{t}-c\right) .
\end{gathered}
$$

${ }^{13}$ The superscript $B$ indicates Bertrand-price competition. 
Under Bertrand-price competition with homogeneous products and identical unit $\operatorname{costs} c$, each firm sets the price equal to unit production $\operatorname{costs} c$. Because all firms have the same unit $\operatorname{costs} c$, we observe a uniform market price $p_{t}^{B^{*}}$. Market demand given this price is split uniformly among all competing firms. No firm earns a profit, because total firm costs correspond to sales. Consequently, total costs and sales behave perfect congruently if the firms make price decisions due to a change of the gross market size $a_{t}$. Proposition 4 states this finding. ${ }^{14}$

Proposition 4 If firms compete in prices on an imperfect market according to the model setup (Bertrand-price competition with homogeneous products and identical unit costs), no asymmetric cost behavior occurs. This is true for both the singlemarket-change and the sequence-of-two-market-changes approach as well as any measurement specification presented in Sect. 2.

Proof The proof follows straightforwardly from inspection of (10) and (11).

\section{Discussion}

An increasing number of empirical research analyses the asymmetric cost behavior in firms using sales as output measure. Most of the literature finds evidence of asymmetric cost behavior and determines several sources such as resource adjustment costs, uncertainties and related beliefs, agency problems, and fixed costs. However, firms also react to changing market conditions by adapting output prices and quantities. We show in an economic model that these market decisions also affect the measured asymmetric cost behavior.

We focus on firms operating in imperfect markets with some freedom in setting output prices. This setting seems more representative than a perfect market with pure price taking firms. We develop a parsimonious model where only conditions of the final product market of a firm change and no established source of asymmetric cost behavior is present. The firm adapts prices and quantities rationally to maximize firm profit. The analysis shows the following results: Market decisions are a source of measured asymmetric cost behavior. The effect of market decisions results from the different impact of the gross market size on costs and sales. Whereas costs are linear in the gross market size, sales are quadratic.

\footnotetext{
${ }^{14}$ However, results change if we relax the assumption of Bertrand-price competition with homogeneous products. Considering Bertrand-price competition with differentiated products, firms set their prices higher than the marginal costs $c$. Then, the total firm costs are linear in the gross market size $a_{t}$, whereas total sales are quadratic. This corresponds to the functional forms of total firm costs and total sales with Cournot-quantity competition. As discussed before, the functional forms of total costs and sales are causing the findings in the Propositions 2 and 3. Hence, the findings obtained in the Cournot setting also occur with Bertrand-price competition with differentiated products and the market decision effect may be a source of measured asymmetric cost behavior for both quantity and price competition. Note that allowing for differentiated products in the Cournot setting yields the same qualitative results as obtained in Propositions 2 and 3.
} 
Customer preferences or their willingness to pay may change. Resulting changes of the demand function causes firms to adapt prices or output quantity. The newly set prices affect measuring the asymmetric cost behavior. This effect occurs in a single-product-firm as well as for each of the products of a multi-product firm. However, changing market conditions may additionally induce a change in the product mix of a multi-product firm. Firm level sales (costs) is the aggregate of the sales (costs) of each single product offered by a firm. Whenever a firm sets new prices for some of the products, the weight of a product within this aggregated information changes too. This might also affect the measured asymmetric cost behavior for firms operating in imperfect markets.

Today, we do not yet know how much of the measured asymmetric cost behavior stems from market decisions. To measure the size of the market decision effect, the output quantities of single products can be used. Then, as our benchmark in Sect. 4 depicts, the market decisions have no impact on the measured asymmetric cost behavior. That is, using output quantities to measure asymmetric cost behavior might be helpful to separate the impact of market decisions from the impact of the established sources. However, firms rarely disclose the output quantities of single products in annual reports, homepages, interviews, or other public information sources. Thus, our results indicate that we need case studies and surveys to learn about the size of the market decision effect and to gain more insights into the sources of the asymmetric cost behavior. Case studies might also assess whether publicly available information is helpful to study the impact of market decisions on the asymmetric cost behavior in archival studies. For example, segment reports in annual reports of firms might be helpful to gather the relevant information to group similar products, whenever product level information is not available. Giving more attention to finer information than firm level sales or costs could improve our understanding of the link between market decisions and the established sources of asymmetric cost behavior like resource adjustment costs, uncertainties and related beliefs, agency problems, and fixed costs.

Acknowledgements Open access funding provided by Vienna University of Economics and Business (WU). Our paper has benefited from detailed and insightful comments of Ralf Ewert (editor) and two anonymous reviewers. For helpful comments on earlier versions of the paper, we thank Kenneth Fjell, Michael Kopel, Ulrich Schäfer, participants of the 2018 EAA Annual Congress, and participants of the 2018 EIASM Workshop on Accounting and Economics.

Open Access This article is licensed under a Creative Commons Attribution 4.0 International License, which permits use, sharing, adaptation, distribution and reproduction in any medium or format, as long as you give appropriate credit to the original author(s) and the source, provide a link to the Creative Commons licence, and indicate if changes were made. The images or other third party material in this article are included in the article's Creative Commons licence, unless indicated otherwise in a credit line to the material. If material is not included in the article's Creative Commons licence and your intended use is not permitted by statutory regulation or exceeds the permitted use, you will need to obtain permission directly from the copyright holder. To view a copy of this licence, visit http://creativecommons.org/licen ses/by/4.0/. 


\section{Appendix}

\section{Proof of Proposition 1}

For the sequence-of-two-market-changes approach, $\varepsilon=0, \alpha=0$, Eqs. (4) and (6), $d e c=0$, and $x_{t, i}^{*}$ instead of $S_{t, i}^{*}$, Eq. (1) yields:

$$
\beta_{1, X}^{C}=\frac{\ln \left(\frac{C_{1, i}^{*}}{C_{0, i}^{*}}\right)}{\ln \left(\frac{x_{1, i}^{*}}{x_{0, i}^{*}}\right)}=\frac{\ln \left(\frac{a_{1}-c}{a_{0}-c}\right)}{\ln \left(\frac{a_{1}-c}{a_{0}-c}\right)}=1 .
$$

Then, $\beta_{1, X}^{C}$ and dec $=1$ is used to calculate $\beta_{2, X}^{C}$ :

$$
\beta_{2, X}^{C}=\frac{\ln \left(\frac{C_{2, i}^{*}}{C_{1, i}^{*}}\right)-\beta_{1, X}^{C} \ln \left(\frac{x_{2, i}^{*}}{x_{1, i}^{*}}\right)}{\ln \left(\frac{x_{2, i}^{*}}{x_{1, i}^{*}}\right)}=\frac{\ln \left(\frac{a_{2}-c}{a_{1}-c}\right)}{\ln \left(\frac{a_{2}-c}{a_{1}-c}\right)}-\beta_{1, x}^{C}=0 .
$$

Analogously, $\beta_{1, X}^{C}=1$ and $\beta_{2, X}^{C}=0$ for the single-market-change approach are obtained.

\section{Proof of Proposition 2}

For the sequence-of-two-market-changes approach, $\varepsilon=0, \alpha=0$, Eqs. (6) and (7), and $d e c=0$, the ABJ specification of Eq. (1) yields:

$$
\beta_{1, A B J}^{C}=\frac{\ln \left(\frac{C_{1, i}^{*}}{C_{0, i}^{*}}\right)}{\ln \left(\frac{S_{1, i}^{*}}{S_{0, i}^{*}}\right)}=\frac{\ln \left(\frac{a_{1}-c}{a_{0}-c}\right)}{\ln \left(\frac{a_{1}+n c}{a_{0}+n c}\right)}+\underbrace{\ln \left(\frac{a_{1}-c}{a_{0}-c}\right)}_{>0} \in(0,1) .
$$

Then, $\beta_{1, A B J}^{C}$ and dec $=1$ is used to calculate $\beta_{2, A B J}^{C}$ :

$$
\beta_{2, A B J}^{C}=\frac{\ln \left(\frac{C_{2, i}^{*}}{C_{1, i}^{*}}\right)-\beta_{1, A B J}^{C} \ln \left(\frac{S_{2, i}^{*}}{S_{1, i}^{*}}\right)}{\ln \left(\frac{S_{2, i}^{*}}{S_{1, i}^{*}}\right)}=\frac{\ln \left(\frac{a_{1}-c}{a_{2}-c}\right)}{\ln \left(\frac{a_{1}+n c}{a_{2}+n c}\right)}+\underbrace{\ln \left(\frac{a_{1}-c}{a_{2}-c}\right)}_{>0}-\beta_{>0}^{C},,
$$




$$
\beta_{1, A B J}^{C}+\beta_{2, A B J}^{C}=\frac{\ln \left(\frac{a_{1}-c}{a_{2}-c}\right)}{\underbrace{\ln \left(\frac{a_{1}+n c}{a_{2}+n c}\right)}_{>0}+\underbrace{\ln \left(\frac{a_{1}-c}{a_{2}-c}\right)}_{>0}} \in(0,1) .
$$

$\beta_{2, A B J}^{C}$ is continuous for $a_{2}<a_{1}$ and continuously differentiable with respect to $a_{2}$ for $a_{2}<a_{1}$ :

$$
\frac{\partial \beta_{2, A B J}^{C}}{\partial a_{2}}=\frac{\left(a_{2}-c\right) \ln \left(\frac{a_{1}-c}{a_{2}-c}\right)-\left(a_{2}+n c\right) \ln \left(\frac{a_{1}+n c}{a_{2}+n c}\right)}{\underbrace{\left(a_{2}-c\right)}_{>0} \underbrace{\left(a_{2}+n c\right)}_{>0} \underbrace{\left(\ln \left(\frac{a_{1}-c}{a_{2}-c}\right)+\ln \left(\frac{a_{1}+n c}{a_{2}+n c}\right)\right)^{2}}_{>0} .}
$$

The nominator of $\frac{\partial \beta_{2, A B J}^{C}}{\partial a_{2}}$ is continuous for $a_{2}<a_{1}$ and is 0 for $a_{2}=a_{1}$. $\frac{\partial}{\partial a_{2}}\left(\left(a_{2}-c\right) \ln \left(\frac{a_{1}-c}{a_{2}-c}\right)-\left(a_{2}+n c\right) \ln \left(\frac{a_{1}+n c}{a_{2}+n c}\right)\right)=\ln \left(\frac{a_{1}-c}{a_{2}-c}\right)-\ln \left(\frac{a_{1}+n c}{a_{2}+n c}\right)>0$ for $a_{2}<a_{1}$ implies that $\left(a_{2}-c\right) \ln \left(\frac{a_{1}-c}{a_{2}-c}\right)-\left(a_{2}+n c\right) \ln \left(\frac{a_{1}+n c}{a_{2}+n c}\right)$ is negative for $a_{2}<a_{1}$. Thus, $\frac{\partial \beta_{2, A B J}^{C}}{\partial a_{2}}<0$ for $a_{2}<a_{1}$, i.e., $\beta_{2, A B J}^{C}$ is monotonically decreasing in $a_{2}$ for $a_{2}<a_{1}$. For $a_{2}=a_{0}, \beta_{2, A B J}^{C}=0$. Then, $\frac{\partial \beta_{2, A B J}^{C}}{\partial a_{2}}<0$ for $a_{2}<a_{1}$ implies that $\beta_{2, A B J}^{C}$ is positive (negative) for $a_{2}<a_{0}\left(a_{2}>a_{0}\right)$. Analogously, the findings for the singlemarket-change approach with the ABJ specification (Eq. (1)) are obtained.

For the sequence-of-two-market-changes approach, $\varepsilon=0, \alpha=0$, Eqs. (6) and (7), and $d e c=0$, the BLS scaled percentage specification of Eq. (3) yields:

$$
\beta_{1, S B L S}^{C}=\frac{c\left(a_{1}-a_{0}\right)(n+1)}{\left(a_{1}-c\right)\left(a_{1}+n c\right)-\left(a_{0}-c\right)\left(a_{0}+n c\right)} \in(0,1) .
$$

Then, $\beta_{1, s B L S}^{C}$ and dec $=1$ is used to calculate $\beta_{2, s B L S}^{C}$ :

$$
\begin{gathered}
\beta_{2, s B L S}^{C}=\frac{c\left(a_{2}-a_{1}\right)(n+1)}{\left(a_{2}-c\right)\left(a_{2}+n c\right)-\left(a_{1}-c\right)\left(a_{1}+n c\right)}-\beta_{1, s B L S}^{C} \\
\beta_{1, s B L S}^{C}+\beta_{2, s B L S}^{C}=\frac{c\left(a_{1}-a_{2}\right)(n+1)}{\left(a_{1}-c\right)\left(a_{1}+n c\right)-\left(a_{2}-c\right)\left(a_{2}+n c\right)} \in(0,1) .
\end{gathered}
$$

For $a_{0}=a_{2}, \beta_{2, s B L S}^{C}$ is 0. For $a_{0}<a_{2}\left(a_{0}>a_{2}\right), \beta_{2, S B L S}^{C}$ is negative (positive). Analogously, the findings for the single-market-change approach with the BLS scaled percentage specification (Eq. (3)) are obtained. 


\section{Proof of Proposition 3}

For the sequence-of-two-market-changes approach, $\varepsilon=0, \alpha=0$, Eqs. (6) and (7), and $d e c=0$, the BLS percentage specification of Eq. (2) yields:

$$
\beta_{1, B L S}^{C}=\frac{\left(a_{1}-a_{0}\right)\left(a_{0}+n c\right)}{a_{1}\left(a_{1}+(n-1) c\right)-a_{0}\left(a_{0}+(n-1) c\right)} \in(0,1) .
$$

Then, $\beta_{1, B L S}^{C}$ and $d e c=1$ is used to calculate $\beta_{2, B L S}^{C}$ :

$$
\begin{gathered}
\beta_{2, B L S}^{C}=\frac{\left(a_{1}-a_{2}\right)\left(a_{1}+n c\right)}{a_{1}\left(a_{1}+(n-1) c\right)-a_{2}\left(a_{2}+(n-1) c\right)}-\beta_{1, B L S}^{C} \\
\beta_{1, B L S}^{C}+\beta_{2, B L S}^{C}=\frac{\left(a_{1}-a_{2}\right)\left(a_{1}+n c\right)}{a_{1}\left(a_{1}+(n-1) c\right)-a_{2}\left(a_{2}+(n-1) c\right)} \in(0,1) .
\end{gathered}
$$

$\beta_{2, B L S}^{C}$ is positive. Analogously, the findings for the single-market-change approach with the BLS percentage specification (Eq. (2)) are obtained.

\section{References}

Anderson SW, Lanen WN (2007) Understanding cost management: what can we learn from the evidence on "sticky costs?". Working paper

Anderson MC, Banker RD, Janakiraman SN (2003) Are selling, general, and administrative costs "sticky"? J Account Res 41:47-63

Anderson MC, Banker RD, Huang R, Janakiraman SN (2007) Cost behavior and fundamental analysis of SG\&A costs. J Account Audit Finance 22:1-28

Balakrishnan R, Gruca TS (2008) Cost stickiness and core competency: a note. Contemp Account Res 25:993-1006

Balakrishnan R, Labro E, Soderstrom NS (2014) Cost structure and sticky costs. J Manag Account Res 26:91-116

Banker RD, Byzalov D (2014) Asymmetric cost behavior. J Manag Account Res 26:43-79

Banker RD, Byzalov D, Chen L (2013a) Employment protection legislation, adjustment costs and crosscountry differences in cost behavior. J Account Econ 55:111-127

Banker RD, Byzalov D, Threinen L (2013b) Determinants of international differences in asymmetric cost behavior. Working paper

Banker RD, Byzalov D, Ciftci M, Mashruwala R (2014) The moderating effect of prior sales changes on asymmetric cost behavior. J Manag Account Res 26:221-242

Banker RD, Byzalov D, Fang S, Liang Y (2018) Cost management research. J Manag Account Res 30:187-209

Calleja K, Steliaros M, Thomas DC (2006) A note on cost stickiness: some international comparisons. Manag Account Res 17:127-140

Cannon JN (2014) Determinants of "sticky costs": an analysis of cost behavior using United States air transportation industry data. Account Rev 89:1645-1672

Chen CX, Lu H, Sougiannis T (2012) The agency problem, corporate governance, and the asymmetrical behavior of selling, general, and administrative costs. Contemp Account Res 29:252-282

Holzhacker M, Krishnan R, Mahlendorf MD (2015) The impact of changes in regulation on cost behavior. Contemp Account Res 32:534-566

Kama I, Weiss D (2013) Do earnings targets and managerial incentives affect sticky costs? J Account Res 51:201-224

Kitching K, Mashruwala R, Pevzner M (2016) Culture and cost stickiness: a cross-country study. Int J Account 51:402-417 
Li W-L, Zheng K (2017) Product market competition and cost stickiness. Rev Quant Financ Acc 49:283-313

Prabowo R, Hooghiemstra R, Van Veen-Dirks P (2018) State ownership, socio-political factors, and labor cost stickiness. Eur Account Rev 27:771-796

Subramaniam C, Watson MW (2016) Additional evidence on the sticky behavior of costs. Adv Manag Account 26:275-305

Tirole J (2001) The theory of industrial organization. MIT Press, Cambridge

Weiss D (2010) Cost behavior and analysts' earnings forecasts. Account Rev 85:1441-1471

Publisher's Note Springer Nature remains neutral with regard to jurisdictional claims in published maps and institutional affiliations. 